\title{
COMPARAÇÃO DE OLEAGINOSAS PARA A PRODUÇÃO DE BIODIESEL
}

\author{
Cinthia da Silva Carreiro da Luz \\ Fernando Benedicto Mainier ${ }^{2}$ \\ Luciane Pimentel Costa Monteiro ${ }^{3}$
}

\begin{abstract}
RESUMO - Atualmente, a matriz energética mundial ainda está com o foco voltado aos combustíveis fósseis, cujas emissões de carbono têm agravado os problemas de poluição atmosférica. Uma alternativa menos poluente são os biocombustíveis, que se diferem por sua origem biológica não fossilizada. Como o Brasil é um dos maiores produtores de soja do mundo, é esta a oleaginosa mais utilizada para a produção do biodiesel brasileiro, não se constituindo, porém, como melhor opção com relação ao rendimento de óleo. $\mathrm{O}$ teor de óleo no grão de soja é de cerca de 19\%, enquanto que canola e girassol apresentam, respectivamente, 38 e $42 \%$. Além disso, a produtividade de óleo (em $\mathrm{kg} / \mathrm{ha}$ ) tanto da canola quanto do girassol também supera a da soja. Além dos 3 óleos já citados (canola, girassol e soja), foram estudados os óleos de coco e milho, totalizando cinco óleos. Foi utilizada a transesterificação com etanol, via catálise básica utilizando o $\mathrm{NaOH}$ como catalisador. $\mathrm{O}$ tempo de reação foi de 30 minutos, com os óleos inicialmente aquecidos a $50^{\circ} \mathrm{C}$, porém as reações ocorreram à temperatura ambiente. A síntese com o óleo de coco apresentou o menor rendimento; as demais (canola, girassol, milho e soja), rendimentos próximos a $70 \%$.
\end{abstract}

PALAVRAS-CHAVE: biodiesel. Oleaginosas, transesterificação

ABSTRACT - Currently, the global energy mix is still with the focus on fossil fuels, whose carbon emissions have compounded the problems of air pollution. A cleaner alternative is biofuels, which differ by their biological origin not fossilized. As Brazil is a major producer of soybeans in the world, this is the crop most used for the production of Brazilian biodiesel, not, however, constitute a better option with respect to oil yield. The oil content in soybeans is about $19 \%$, while canola and sunflower have respectively 38 and $42 \%$. Furthermore, the oil yield ( $\mathrm{kg} / \mathrm{ha}$ ) so as canola sunflower also overcomes the soybeans. Besides the already mentioned 3 oils (canola, sunflower and soybeans), coconut oils and corn were studied, totaling five oils. Transesterification with ethanol was used, via base catalysis using $\mathrm{NaOH}$ as a catalyst. The reaction time was 30 minutes, with the oils initially heated at $50{ }^{\circ} \mathrm{C}$, although the reactions occurred at room temperature. The synthesis with coconut oil showed the lowest yield; other (canola, sunflower, corn and soybeans), yields close to $70 \%$.

KEY-WORDS: biodiesel, oil plants , transesterification

\footnotetext{
${ }^{1}$ Universidade Federal Fluminense e Instituto Federal do Rio de Janeiro

${ }^{2}$ Universidade Federal Fluminense, Mestrado Acadêmico em Engenharia Química

${ }^{3}$ Universidade Federal Fluminense, Mestrado Acadêmico em Engenharia Química
} 


\section{INTRODUÇÃO}

O presente trabalho se propôs a estudar, em nível de escala laboratorial, os rendimentos em ésteres a partir da transesterificação com os óleos de canola, coco, girassol, milho e soja. Foram considerados também outros dados em literatura, como teor de óleo na semente e a produtividade de óleo por área plantada, a fim de serem identificadas as melhores opções para a produção de biodiesel.

A matriz energética mundial ainda é muito dependente dos combustíveis fósseis que é um bem não renovável. É sobre esse aspecto que muitos sustentam a tese de que devemos buscar uma alternativa aos combustíveis fósseis. Porém, mesmo que isso seja um fato incontestável, ainda há uma oferta grande de petróleo no mundo. No ano de 2012, tanto a capacidade de refino quanto o consumo mundial de petróleo não ultrapassaram a casa dos 35 milhões de barris, enquanto as reservas provadas de petróleo ultrapassaram a marca de 1,5 trilhão de barris. (ANP, 2013). Sendo assim, a substituição do petróleo como matéria-prima nãorenovável pode não ser tão urgente. Contudo, há uma condição inegável sobre os problemas causados pelos combustíveis fósseis: o aumento dos Gases de Efeito Estufa (GEE).

A queima de um combustível no geral, sendo fóssil ou não, emite $\mathrm{CO}_{2}$. Um combustível renovável, oriundo da biomassa, pode ser considerado "carbono neutro", uma vez que o $\mathrm{CO}_{2}$ emitido foi previamente consumido pela planta devido à fotossíntese, que retira o $\mathrm{CO}_{2}$ do ambiente e libera $\mathrm{O}_{2}$. Os combustíveis de origem fóssil, ao contrário, não são considerados "carbono neutro", pois a queima destes faz aumentar consideravelmente os níveis de $\mathrm{CO}_{2}$ da atmosfera, sendo os grandes centros urbanos os lugares mais afetados, devido ao grande número de automóveis movidos à combustão.
Para minimizar essa forte dependência aos combustíveis fósseis, surgem os automóveis bicombustíveis, popularmente conhecidos como flex, cujo motor tipo Otto funciona tanto com álcool quanto com gasolina, sendo necessárias algumas alterações nos motores para que ele possa funcionar com os dois combustíveis.

A gasolina já possui o seu substituto renovável - o etanol. O biodiesel, de igual modo, se apresenta como o substituto renovável para o diesel fóssil, com a vantagem de não serem necessárias grandes mudanças nos motores Diesel, sendo possível utilizar qualquer proporção de biodiesel/diesel.

\subsection{Matérias-primas e o potencial brasileiro.}

O Brasil é o país com um grande potencial para a produção de energia renovável por possuir vantagens agrônomas, uma vez que o clima é tropical, com altas taxas de luminosidade e temperaturas médias anuais, disponibilidade hídrica e variedade de opções de cultivo de oleaginosas. A oleaginosa mais produzida em solo nacional é a soja e o Brasil é o segundo maior produtor de soja do mundo, perdendo apenas para os Estados Unidos. A produção da soja brasileira fechou o ano de 2012 com 66,68 milhões de toneladas, enquanto que a americana marcou 83,17 milhões de toneladas (Brasil, 2013). Sendo assim, a soja é a escolha para a produção do biodiesel nacional, não sendo, porém, a que apresenta o melhor rendimento anual de óleo em tonelada por hectare. Existem outras oleaginosas que podem apresentar até o dobro desse rendimento, conforme demonstrado na Tabela 1(PEQUENO,210). 
Tabela 1 - Rendimento anual de óleo

\begin{tabular}{cc}
\hline RENDIMENTO DE ÓLEO (t/ha ano) \\
\hline Algodão & $0,1-0,2$ \\
Amendoim & $0,6-0,8$ \\
Canola & $0,5-0,9$ \\
Coco & $0,3-1,4$ \\
Dendê & $3-6$ \\
Girassol & $0,5-1,5$ \\
Mamona & $0,5-1,0$ \\
Milho & $0,18-0,36$ \\
Pinhão Manso & $1-6$ \\
Soja & $0,2-0,6$ \\
\hline
\end{tabular}

Fonte: PEQUENO (2010)

Por se tratar de uma fonte que é destinada à alimentação, e que o aumento do consumo do biodiesel implicará numa maior demanda por terras agricultáveis, é importante que a oleaginosa escolhida para fins energéticos tenha um bom rendimento anual de óleo por área plantada. Além disso, seu óleo deve ter um bom rendimento em éster.

\subsection{Reação de Transesterificação}

Para transformar o óleo, fonte de4 triacilglicerídeos em biodiesel, pode-se utilizar a transesterificação, que consiste basicamente na retirada da molécula de glicerol do óleo, conforme ilustrado na Figura 1, em que o triacilglicerídeo reage com um álcol de cadeia curta, como metanol ou etanol, na presença de um catalisador. Após a reação, tem-se a formação de duas fases: um arica em glicerol, mais denso, e a outra em biodiesel, menos denso. Tais fases podem ser separadas por decantação ou centrifugação (Costa, 2009).

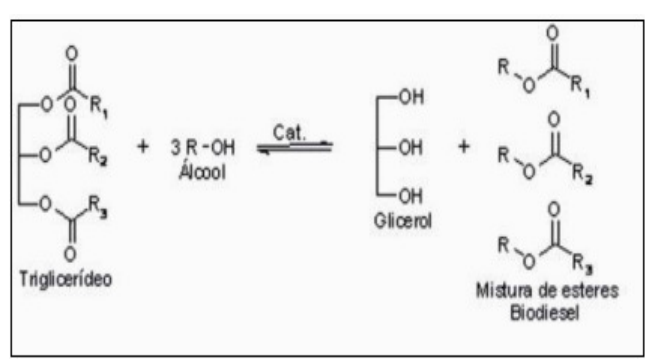

Figura 1 - Reação de Transesterificação. Fonte: COSTA, 2009

Pela estequiometria da reação são necessários 3 mols de álcool para cada mol de triglicerídeo. Como a reação é reversível, um excesso de álcool provocará o deslocamento do equilíbrio no sentido dos produtos, aumentando o rendimento dos ésteres. Algumas variáveis influenciam a reação de transesterificação, a saber: pureza dos reagentes, razão molar álcool/óleo, temperatura de reação, catalisador e agitação(Costa,2009).

Do ponto de vista técnico, a rota metílica é mais simples, tendo o tempo de reação menor, separação das fases éster e glicerina mais espontânea, altas taxas de conversão e necessidade de um pequeno excesso de álcool. Porém, o metanol é altamente tóxico, é oriundo de fontes nãorenováveis, além de o Brasil não ter autossuficiência na sua produção. Em contrapartida, o etanol possui baixa toxicidade e é produzido de fontes renováveis. Além disso, o Brasil é um dos maiores produtores de etanol do mundo. (Costa, 2009)

Com relação ao tipo de catálise, a reação pode ocorrer numa via catalítica homogênea (ácida ou básica) ou heterogênea.

$\mathrm{Na}$ catálise básica homogênea, geralmente são utilizados os hidróxidos de metais alcalinos, carbonatos e alcóxidos de metais alcalinos (metóxido de sódio, etóxido de sódio, propóxido de sódio e butóxido de sódio). (Castro, 2009 apud Ma e Hanna, 1999). Industrialmente, é a via mais indicada, pois é mais rápida do que a 
catálise ácida homogênea, além de os catalisadores alcalinos serem mais facilmente manipuláveis e menos corrosivos do que os catalisadores ácidos. (Costa, 2009). Esta via ocorre à pressão atmosférica, com temperaturas amenas, e menor razão molar álcool/óleo, se comparada com a catálise ácida homogênea. (Melo Jr., 2008)

Os alcóxidos de metal alcalino são os catalisadores mais ativos, com rendimentos elevados ( $>98 \%)$ em curtos períodos de reação (30 minutos), mesmo em baixas concentrações $(0,5 \mathrm{~mol} \%)$. No entanto, requerem a ausência de água, uma vez que esta dá origem à hidrólise de uma parte do éster produzido, com a consequente formação de sabão. Esta reação de saponificação reduz os rendimentos de éster e dificulta o processo de separação das fases (Schuchardt et al., 1998). Outra característica dos reagentes, para este caso, está relacionada ao índice de acidez, resultante da presença dos ácidos graxos livres no óleo. Tais ácidos irão consumir o catalisador básico, comprometendo o desenvolvimento da reação. (Ma e Hanna, 1999)

A catálise ácida homogênea é a mais comum e, o catalisador mais utilizado é o ácido sulfúrico $\left(\mathrm{H}_{2} \mathrm{SO}_{4}\right)$. Essa via catalítica é utilizada principalmente na produção de biodiesel a partir de resíduos com altos teores de ácidos graxos livres. Para as reações de transesterificação, a catálise ácida possui o inconveniente de requer uma alta razão molar álcool: óleo, exigir altas temperaturas e demandar longos períodos de síntese (Silva, 2005).

A catálise heterogênea é uma alternativa aos problemas encontrados na catálise homogênea, tais como: maior número de etapas; purificação dos produtos; possibilidade de corrosão do reator (catálise ácida); saponificação (catálise básica); atividade baixa frente a alcoóis de maior massa molar. Possui como vantagens: facilidade de purificação dos ésteres monoalquílicos, permite a reutilização dos catalisadores, minimiza a geração de efluentes e facilita consideravelmente a recuperação e a purificação da glicerina. Os catalisadores mais utilizados são: zeólitas, óxidos e sais inorgânicos, resinas trocadoras de íons, ácidos e bases orgânicos e materiais lamelares. (Melo Jr., 2008)

\section{MATERIAIS E MÉTODOS}

O foco do presente estudo foi a comparação do rendimento em éster a partir da transesterificação dos óleos de canola, coco, girassol, milho e soja. Além da produção de éster, em escala laboratorial, foram considerados dados que são anteriores à etapa da reação, tais como os rendimentos anuais de óleo de cada grão/fruto por área plantada.

Escolheu-se utilizar a etanólise, via catálise básica $(\mathrm{NaOH})$, com excesso de $100 \%$ de etanol, para cinco óleos, a saber: canola, coco, girassol, milho e soja. Os óleos de canola, girassol, milho e soja eram da marca Qualitá e o óleo de coco da marca Vila Ervas. O óleo de coco apresentou um aspecto solidificado a temperaturas inferiores a $25^{\circ} \mathrm{C}$, devido à grande quantidade de ácido láurico.

Primeiramente, levou-se o óleo para o aquecimento, até $50{ }^{\circ} \mathrm{C}$ em Banho Maria (Novatecnica). Em seguida, preparou-se o etóxido de sódio, dissolvendo-se o $\mathrm{NaOH}$ em álcool etílico absoluto P.A. num erlenmeyer com tampa. Deve-se tomar cuidado com essa etapa, para que a umidade do ambiente não contamine o alcóxido, a fim de evitar a reação de saponificação.

O óleo aquecido e o alcóxido foram levados à placa de agitação magnética modelo EEQ-9010. O controle de agitação foi mantido em 4 (numa escala de 0 a 10 rpm), mas aquecimento da placa permaneceu desligado. Um vidro de relógio foi acomodado na boca do becher, 
para minimizar a evaporação do etanol. A reação ocorreu por 30 minutos e, transcorrido esse tempo, a mistura reacional foi levada a um funil de decantação, onde permaneceu por, no mínimo, 24h. Passado esse tempo, observou-se a separação em duas fases. A fase mais densa (glicerol) foi descartada; a menos densa seguiu para o processo de neutralização com ácido clorídrico, lavagem com água e posterior secagem com $\mathrm{Na}_{2} \mathrm{SO}_{4}$. gravimetria.

O teor de éster é calculado por

\section{RESULTADOS E DISCUSSÃO}

A etanólise alcalina de óleos vegetais é, comumente, conduzida a temperaturas próximas ao ponto de ebulição do álcool, porém, temperaturas acima de $60{ }^{\circ} \mathrm{C}$ devem ser evitadas, para minimizar a ocorrência da reação de saponificação.

A reação ocorreu por 30 minutos, numa placa de agitação, onde somente a agitação foi acionada, não o aquecimento. Os óleos foram previamente levados ao banho-maria a $50^{\circ} \mathrm{C}$. Escolheu-se aquecer os óleos no banho e não na placa para que a distribuição de temperatura fosse mais uniforme e mais fácil de ser controlada pelo banho permitir um controle constante da temperatura.

Todas as sínteses apresentaram um leve escurecimento no início da reação, porém a síntese com o óleo de soja apresentou uma característica diferente. $\mathrm{O}$ escurecimento, no momento da adição de alcóxido, para a soja, foi bastante intenso no início. Mas, com o decorrer da reação, a coloração foi ficando menos intensa até se tornar castanha, conforme demonstra a Figura 2. PELISSON (2013) mencionou, em seu trabalho, o mesmo escurecimento, porém sem explicar o motivo.

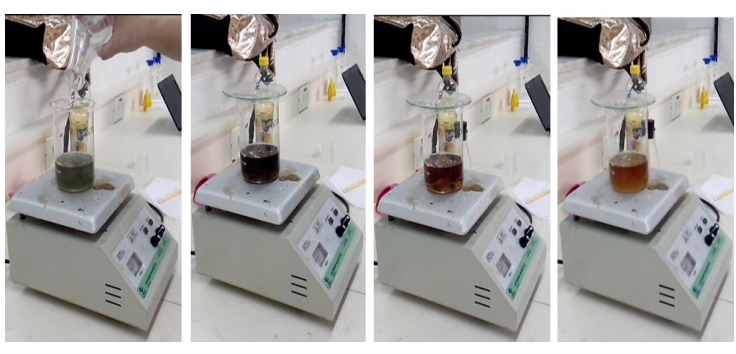

Figura 2 - Transesterificação do óleo de soja, em quatro momentos.

Provavelmente, essa diferença de coloração deve-se à lecitina, quimicamente denominada fosfatídeo ou fosfolipídio. A lecitina é removida do óleo bruto no processo de degomagem do óleo e apresenta coloração âmbar. Diferentes oleaginosas apresentarão diferentes teores de fosfatídeos, porém a soja se destaca dentre as demais oleaginosas, podendo alcançar teor de fosfatídeo em torno de 3\% no óleo bruto. Durante o processo de degomagem somente os fosfolipídios hidratáveis são extraídos, permanecendo os não hidratáveis, sendo estes os responsáveis pela coloração marrom quando aquecidos. (Castejon, 2010)

Após a reação, decorrido um período de $24 \mathrm{~h}$, notou-se a formação de duas fases em todas as sínteses, exceto àquela realizada com o óleo de coco. Sendo assim, foi adicionada glicerina no funil de separação que continha a síntese com o óleo de coco para facilitar a visualização das duas fases, conforme ilustrado na Figura 3. 


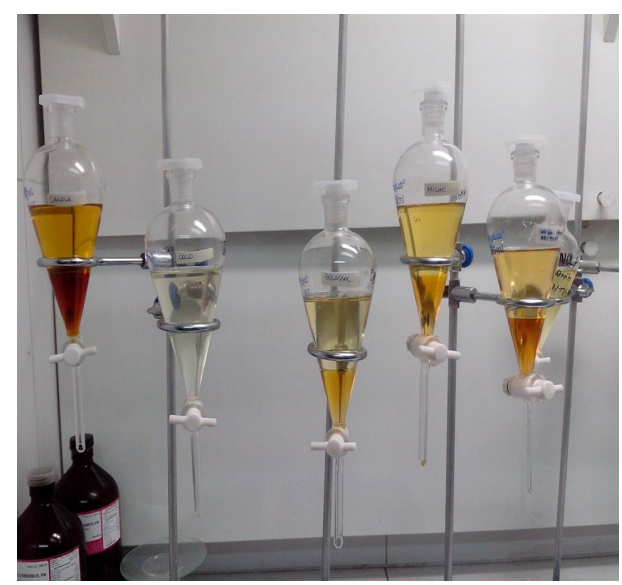

Figura 3 - Separação de fases gliceroléster de canola, coco, girassol, milho e soja

A primeira lavagem foi feita com uma água levemente acidificada com $\mathrm{HCl}$ para neutralizar o catalisador básico, bem como retirar o excesso de álcool da fase éster. Nessa etapa, notou-se que na fase aquosa (mais densa) houve a formação de sabão, devido, possivelmente, ao óleo que não reagiu, conforme ilustrado na Figura 4. Neste caso, a ocorrência da reação de saponificação mostra-se interessante para retirar o óleo que ainda não havia reagido, ficando na fase éster essencialmente o biodiesel. No caso de saponificação a corrida não foi considerada adequada para produção do biodiesel.

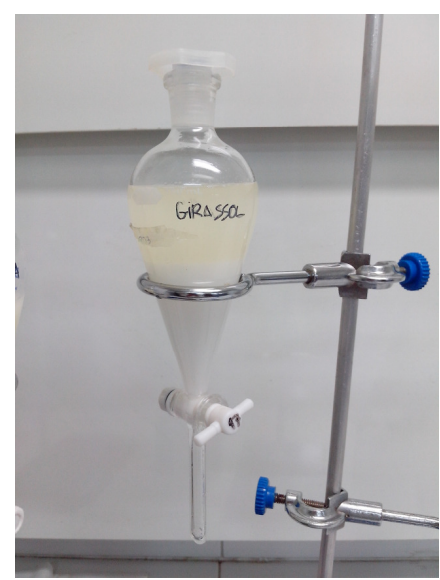

Figura 4 - Primeira lavagem

A fase aquosa teve seu $\mathrm{pH}$ medido e foi, em seguida, neutralizada e descartada. A segunda lavagem foi realizada apenas com água deionizada. Esse processo se repetiu até que a água de lavagem ficasse mais límpida e com o pH neutro.

$\mathrm{O}$ processo de lavagem tornou $\mathrm{o}$ éster hidratado, sendo o conteúdo de água de cerca de $10 \%$. Portanto, para retirar a água, foi adicionado $\mathrm{Na}_{2} \mathrm{SO}_{4}$, que foi em seguida filtrado, resultando num éster com um menor teor de água.

Comparou-se os cinco óleos estudados (canola, coco, girassol, milho e soja), sendo considerado, além do rendimento em óleo por área cultivada, a produção de éster de cada óleo. Tais dados estão elencados na Tabela 3.

Tabela 3 - Comparação de rendimentos de ésteres

\begin{tabular}{cccc}
\hline & $\begin{array}{c}\text { RENDIMENTO } \\
\text { DE ÓLEO (t/ha } \\
\text { ano) }\end{array}$ & $\begin{array}{c}\text { RENDIMENTO } \\
\text { DE ÉSTER (\%) }\end{array}$ & $\begin{array}{c}\text { RENDIMENTO } \\
\text { DE ÉSTER } \\
\text { (t/ha ano) }\end{array}$ \\
\hline Canola & $0,5-0,9$ & $72,61 \%$ & $0,36-0,65$ \\
\hline Coco & $0,3-1,4$ & $66,86 \%$ & $0,20-0,94$ \\
\hline Girassol & $0,5-1,5$ & $71,28 \%$ & $0,36-1,07$ \\
\hline Milho & $0,18-0,36$ & $71,40 \%$ & $0,13-0,26$ \\
\hline Soja & $0,2-0,6$ & $72,51 \%$ & $0,15-0,44$ \\
\hline
\end{tabular}

À exceção do coco, todas as outras oleaginosas apresentam rendimento de éster em torno de $72 \%$, porém tanto canola quanto girassol têm altos rendimentos anuais em tonelada por hectare de óleo e apresentam também bons rendimentos em produção de éster, podendo atingir valores maiores do que o dobro do rendimento com a soja, que é a oleaginosa mais utilizada para a produção do biodiesel brasileiro.

A formação de glicerina, apesar de ser, a princípio, indesejável, poder ser um produto com alto valor comercial, especialmente na indústria cosmética, podendo trazer vantagens econômicas à produção do biodiesel.

Com relação ao preço do óleo 
refinado, têm-se observado atualmente que o de soja é o mais barato; os óleos de girassol e milho tem o custo de, aproximadamente, o dobro do de soja e o de canola é ligeiramente mais caro do que estes dois. O preço do óleo de coco é extremamente alto, podendo ser até 30 vezes maior do que o da soja, tornando-o pouco competitivo em termos econômicos. (ANP,2013)

\section{CONCLUSÃO}

A finitude dos combustíveis fósseis é evidente, o que torna urgente a busca por combustíveis que lhes sejam alternativos, não só pela questão da futura escassez das reservas, mas também pela qualidade atmosférica. As grandes cidades, principalmente, vêm sofrendo com a qualidade do ar que, dia após dia, tem se tornado pior.

O biodiesel veio para ser o substituto renovável do diesel, assim como o álcool o é para a gasolina, sendo a soja a oleaginosa mais utilizada para a produção do biodiesel brasileiro. $\mathrm{O}$ teor de óleo em seus grãos é de 19\%; outras oleaginosas, no entanto, apresentam o dobro ou mais de rendimento em óleo, como é o caso da canola e girassol, respectivamente. Além disso, o rendimento de óleo por área, tanto da canola, quanto do girassol, também superam o da soja.

Com a indústria do biodiesel ainda incipiente, talvez essa diferença de números bastante sutil não provoque um grande impacto. Porém, a busca por uma oleaginosa que apresente uma menor demanda por terras deve ser avaliada. Com a diminuição da oferta do combustível fóssil haverá, consequentemente, o aumento do consumo do combustível renovável. Isso implicará numa maior demanda por terras para o cultivo de oleaginosas destinadas ao biocombustível. Com o processo de expansão das fronteiras agrícolas, há de se pensar numa oleaginosa que tenha uma grande produção de óleo numa menor área de cultivo; e que esse óleo dê um bom rendimento em éster. E, nesses quesitos, tanto a canola, quanto o girassol se encaixam muito bem, o que as tornam boas opções à soja para a produção do biodiesel.

\section{REFERÊNCIAS}

ANP. Anuário Estatístico Brasileiro do Petróleo, Gás Natural e Biocombustíveis 2013.

BRASIL. Ministério da Agricultura, Pecuária e

Abastecimento. Anuário estatístico de agroenergia 2012. Brasília. 2013.

CASTEJO, Letícia Vieira. Estudo da Clarificação da Lecitina de Soja. Dissertação de

Mestrado. Programa de Pós-Graduação em

Engenharia Química. Universidade Federal de

Uberlândia. Uberlândia. MG. 2010

CASTRO, B. C. 2009. Otimização das Condições da Reação de Transesterificação e Caracterização dos Rejeitos dos Óleos de Fritura e de Peixe para Obtenção de Biodiesel. Dissertação (Mestrado em Ciências). - Universidade Federal do Rio de Janeiro, Escola de Química, Programa de Pós-Graduação em Tecnologia de Processos Químicos e Bioquímicos, Rio de Janeiro.

CONAB. Companhia Nacional de Abastecimento. 2013. Acompanhamento da safra brasileira de grãos. - v. 1, n.1. Brasília..

COSTA, Patrícia Pinto Kalil Gonçalves. Catalisadores químicos utilizados na síntese de biodiesel. Brasília, DF: Embrapa Agroenergia, 2011.

MA, F.; HANNA, M. A. 1999. Biodiesel production: a review. Bioresource Technology, 70, 1 - 15. 
MELO JR, C. A. R. 2008. Esterificação catalítica e não-catalítica para síntese de biodiesel em reator micro-ondas. Dissertação (Mestrado em engenharia de processo). Universidade Tiradentes. Aracaju.

PELISSON. 2013. Leidimara. Produção de biodiesel por meio de fluidos pressurizados e sua caracterização utilizando Cromatografia Gasosa de Alta Resolução (HRGC). Tese de Doutorado. USP. São Carlos.

PEQUENO; 2010. Marcos Antonio Gomes. Avaliação do potencial produtivo de óleos obtidos a partir de microalgas por cromatografia gasosa. Dissertação de Mestrado. UFPB.

SANTOS, W. F; AFFÉRI, S. F; REINA, E.; PELUZIO, J. M.; SILVA, M. C. de C.; DOTTO, M. A. 2012. Teores de Óleo em Populações de Milho, sob Alto e Baixo Nitrogênio em Palmas, na Safra de 20102011. XXIX Congresso Nacional de Milho e Sorgo. Águas de Lindóia.

SCHUCHARDT, U.; SERCHELI, R.; VARGAS, R. M. Transesterification of vegetable oils: a review. J. Braz. Chem. Soc.[online]. 1998, vol.9, n.3 [cited 201306-24], pp. 199-210.

SILVA, C. L. M. Obtenção de ésteres etílicos a partir da transesterificação da andiroba com etanol. Dissertação (Mestrado em Química). Unicamp. São Paulo. 2005. 